Science Life

\title{
SOUL. HEART. SURGERY
}

\author{
Academic lecture at the General Meeting of the Latvian Academy of Sciences, 24 November 2016, \\ on the occasion of awarding the Grand Medal of the Latvian Academy of Sciences \\ to Romans Lācis for an important contribution to the development of cardiac surgery in Latvia
}

\author{
Romans Lācis \\ Professor, Dr. habil. med. \\ Pauls Stradiṇš Clinical University Hospital, Latvia
}

In the Antiquity, 3500-5000 and even 6000 years BC, to preserve the body for afterlife, the mummies of the deceased were created. It was important for the Soul, passing through a defined cycle, to return and find a place (the body) for a real afterlife. The site, the abode of the Soul was the heart.

Nowadays, the examination of mummies with the computed tomography (CT) method has revealed, that even in the ancient world, 3500-6000 years BC, a variety of vascular and heart diseases were common, and they could also be the cause of death. For example, Adell H. Allam et al., in 2011 (Journal of the American College of Cardiology, 2011, 4, 315-327), published the data on 52 mummies, investigating which in 44 cases vascular and cardiac structures could be identified, of which 20 showed signs of arteriosclerosis with calcification of vascular walls. Severe cardiac coronary atherosclerosis with calcification was found in two mummies $\left(1550^{\text {th }}-1580^{\text {th }} \mathrm{BC}\right)$. This discovery is the oldest documented evidence of coronary atherosclerosis in humans many centuries before the beginning of our era.

Cardiovascular disease is the leading cause of death today, killing more than 17 million people a year (2010). Sadly, the forecast of experts, epidemiologists is quite negative. It is anticipated that in 2030 there will be over 23 million deaths brought about by this pathology — cardiovascular disease. And all of this - in spite of very extensive preventive actions taken to control the disease.

Already in 1852, with the autopsy method, Johann Nepomuk Czermak found atherosclerosis in a 3000-yearold Egyptian female mummy (Czermak, Mr N. Description and microscopic findings of two Egyptian mummies. S.B. Akad. Wiss. Wien, 9, 1852, 427). The contemporary CT scanning allows to conduct the research without damaging the mummies that are extremely valuable to the science. Atherosclerosis was found in 20 of 44 examined mummies, i.e., in $45 \%$ of cases.

The modern CT studies allowed M. A. Allison et al. (2004), while examining 650 asymptomatic 50-60-year-old fellow human beings, to discover that artery atherosclerosis is observed in $92 \%$ of men and $72 \%$ of women, but, as they reach a certain age -60 years (men) and 70 years (women) $-100 \%$ calcinosis is found in one or more arteries. (Allison, M. A., Criqui, M. H., Wright, C. M. Patterns and risk factors for Systemic calcified atherosclerosis. Arterioscler. Thromb. Vasc. Biol., 24, 2004, 331-336).

An alarmingly high occurrence and mortality from cardiovascular disease is the reason for exceptional public attention focussed on the search for solutions. Of course, the activities are directed toward prevention - the measures to reduce the rate of new cases. These measures include promoting a healthy living regime, cardiovascular disease adjustable risk management and control.

Undeniably, timely treatment of patients is of a great importance. One group of diseases - cardiovascular disease still is the main cause of death in the world's population. Within only one year, 17 to 17.5 million people die. It is a much greater number than those that pass away in war, violence, due to injuries, more than those killed by oncologic diseases and other illnesses.

In Latvia, cardiovascular disease is common and the cause of death is more than $50 \%$ of all deaths. It is the leading cause of death in the country.

Statistical data show that in 2015 a total of 28179 people died in Latvia, of which 16135 passed away because of cardiovascular pathology. It amounts to $57 \%$. This is an acute and disturbing fact. It is estimated that in Latvia about $19 \%$ of the population suffer from cardiovascular pathology, which accounts for approximately 380000 people. According to forecasts of international experts, the disease epidemiologists regarding the increase in mortality, this trend is clearly marked also in Latvia. For instance, in 2011, per 100 000 of the population, 776.1 people died of cardiovascular diseases, in 2011, this number was 760.9, in $2012-801.9$, in $2013-812.8$, in $2014-806.1$ and in $2015-815.9$ people.

The world has responded with very extensive, massive, financially very costly treatment and prevention activities. Cardiology and cardiac surgery centres have been created. Changes of national legislation have been introduced in or- 
der to promote a healthy lifestyle, to limit the disease risk factors. For example, a ban on smoking in public places, on aircraft, near schools, on the street, on balconies, etc. Catering in schools is adjusted, physical activity programmes changed, etc. In Latvia, prevention and treatment of cardiovascular disease generally have gained very much attention. A well-equipped cardiology assistance service has been established, two cardiac centres created - in Pauls Stradiňš Clinical University and the Children's Clinical University Hospital. All this, undoubtedly, has an important, positive result even in a very short period, within a few years. The Central Statistical Bureau of Latvia indicates that mortality caused by a particularly serious disease - myocardial infarction - is significantly reduced. In 2009, per 100000 inhabitants, myocardial infarction caused the death of 70.5 people, but already in 2015 - only of 59.2 people. It is an excellent result. Unfortunately, similar dynamics is not observed regarding the so-called cerebrovascular disease, hypertensive disease, and cardiomyopathy.

The Latvian Cardiovascular Surgery Centre was created in 1969 following the decision of the Ministry of Health (Minister V. Kaṇeps). Professor Jānis Volkolākovs was appointed a director of the Centre. Many important directions were developed: surgery of congenital heart ailments, correction of heart valve abnormalities, myocardial revascularisation, aortic disease surgery, peripheral arterial and venous surgery, heart rhythm disorders surgery with different types of pacemakers, implantation of defibrillators, cardiac tumour surgery, heart failure surgery using mechanical assisted circulation methods, as well as a heart transplant from person to person. At that time, virtually everything was unknown, new, both here and throughout the world. This direction, cardiovascular surgery, was just taking shape, and it rapidly developed. The first "closed" mitral commissurotomy took place on 30 March 1957 in Pauls Stradiņ̌ Hospital, and it was carried out by the outstanding Latvian surgeon, a surgeon with golden hands, Professor Ēvalds Ezerietis.

The decision to establish the Cardiovascular Surgery Centre in 1969 in Latvia was very progressive and absolutely timely. Mortality from cardiovascular disease in those years was high, and the existing resources and experience was divided among different Latvian hospitals. Therefore, uniting everything in a single centre, the experience of Pauls Stradiņš Clinical Hospital, Riga City $1^{\text {st }}$ Hospital, Military Hospital, and Children's Hospital was consolidated. As a result, not only the experience, but also human resources and partially the then existing equipment was concentrated in a single place. The initial significant experience in heart surgery was accumulated at the Riga City $1^{\text {st }}$ Hospital — by Dr Anatolijs Nikitins, Ojārs Aleksis. At the Military Hospital, heart surgeries were performed by Dr. Valentīns Harlamovs. In Pauls Stradiņš Hospital, cardiac surgery pioneers were professors Ēvalds Ezerietis, Jānis Slaidin̨š, and Vladimirs Utkins, Dr. Uldis Bērziņš and Dr. Natālija Bāliņa. The most vigorous activity was at the Children's Hospital under the leadership of Professor Aleksandrs Bieziņš — profes- sors Jānis Gaujens, Jānis Volkolākovs, Oḷğerts Putniņš, Herberts Zandersons, Visvaldis, and Valija Ledus, Dr. Juris Lejassauss, Dr. Juris Breicis, Juris Jansons, Māris Ligers, Āris Lācis, etc. Those people formed the core of the Cardiovascular Surgery Centre and shaped this institution, which was acutely needed in Latvia.

The further developers of the newly established Cardiovascular Surgery Centre were also Pauls Stradiņ̌̌ Hospital surgeons Uldis Bērziņš, Maruta Skujiņa, Andris Aivars, Biruta Puriņa, Ivars Jaunkalns, Biruta Mamaja, Augusts Ozols, Heinrihs Lācis, Pēteris Ošs, Edvīns Lietuvietis, Svetlana Thora, Igors Marcinkevičs, Andris Alks, anaesthetists Biruta Timofejeva, Olafs Radziņš, Laila Feldmane, and many, many others. Founding of the Centre was also associated with the accumulated initial experience in heart surgery at the Military Hospital (V. Harlamovs), Riga City $1^{\text {st }}$ Hospital (A. Nikitins, O. Aleksis), as well as the Children's Hospital.

The original development since 1969 had been very complicated and demanding, because the insufficient experience was largely due to the limited opportunities to purchase the expensive technology. The road was thorny. At that time, in the 1970s, heart surgery was evolving globally. Good professional, collegial contacts developed with cardiac surgery centres in many universities. In my opinion, the paramount role in supporting cardiac surgery was played by the alliance created at that time: academic department, hospital and research laboratory. Their work was coordinated and highly focussed. I think, the creator of this alliance was Professor Anatolijs Blugers, once very popular in Latvia.

The Latvian Cardiosurgical Centre, working under the guidance of professor Jānis Volkolākovs, has mostly retained the previous trends of activities and continues to develop them in a new quality. They include valvular heart surgery, myocardial revascularisation, ascending aortic surgery, surgical correction of heart rhythm disorders, treatment of heart failure by means of mechanical ventricles and heart transplants.

A great revolutionary event took place on 10 April 2002 a successful heart transplantation was carried out. The experience accumulated to date encompasses 24 transplant operations, in 2015 - a successful heart transplantation to a child.

The most vivid moments in the development of the Centre:

1. The professional recognition extended by the superpower of the time to professor John Volkolākovs, granting the State Prize for achievements in the development of cardiac surgery (1977).

2. Stabilisation of the quality and supply of medical technology after the restoration of Latvia's independence.

3. Increase of assistance to residents of Latvia, since 2007, with opportunities to perform more than 1000 operations with artificial vasculature and increase of the survival rate 


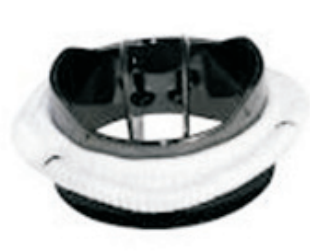

Fig. 1. Heart valve mechanical prostheses.

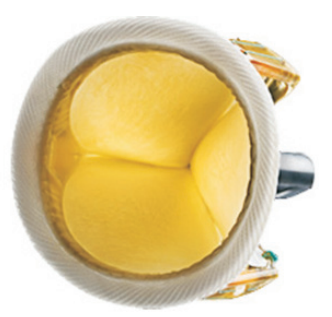

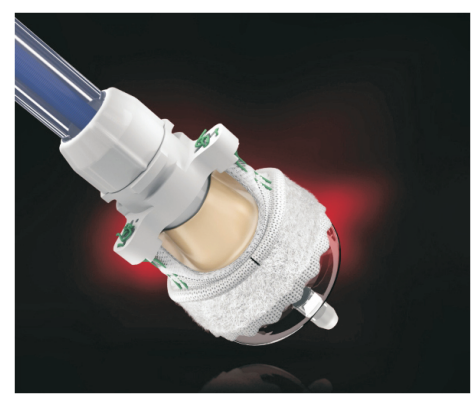

Fig. 2. Edwards Lifesciences xenopericardial bioprosthesis Intuity.

Fig. 3. St. Jude Medical xenopericardial bioprosthesis Trifecta.

after these operations up to $99 \%$ and more. In 2014, a heart surgery under artificial vasculature conditions was carried out on 1089 patients and in 2015 - on 1107 patients. The most advanced heart valve mechanical and biological prostheses have been used. (Figs. 1, 2 and 3).

4. The possibility of a heart transplant and its successful realisation in 2002 and HTx on a child in 2015.

5. Mechanical ventricular implantation with excellent results for 35 patients. (Figs. 4, 5).

6. Very successful introduction of transcatheter heart valve surgery, the so-called hybrid operations since 2009 have shown truly competitive results in Europe. (Figs. 6, 7)

Looking into the history of development and formation, the most important aspect must be noted - continuity and assertive, targeted daily work of the great staff of the Latvian Cardiology Centre. Its motto - Salus aegroti suprema lex - has indeed always been the main driving and motivating force. This theme must always be retained, and carried into the future.

And yet the question remains: What is the heart?! A pump? The power centre? The prohibited organ? Abode of the soul? The Sun?

In any case - the heart is not just a pump!
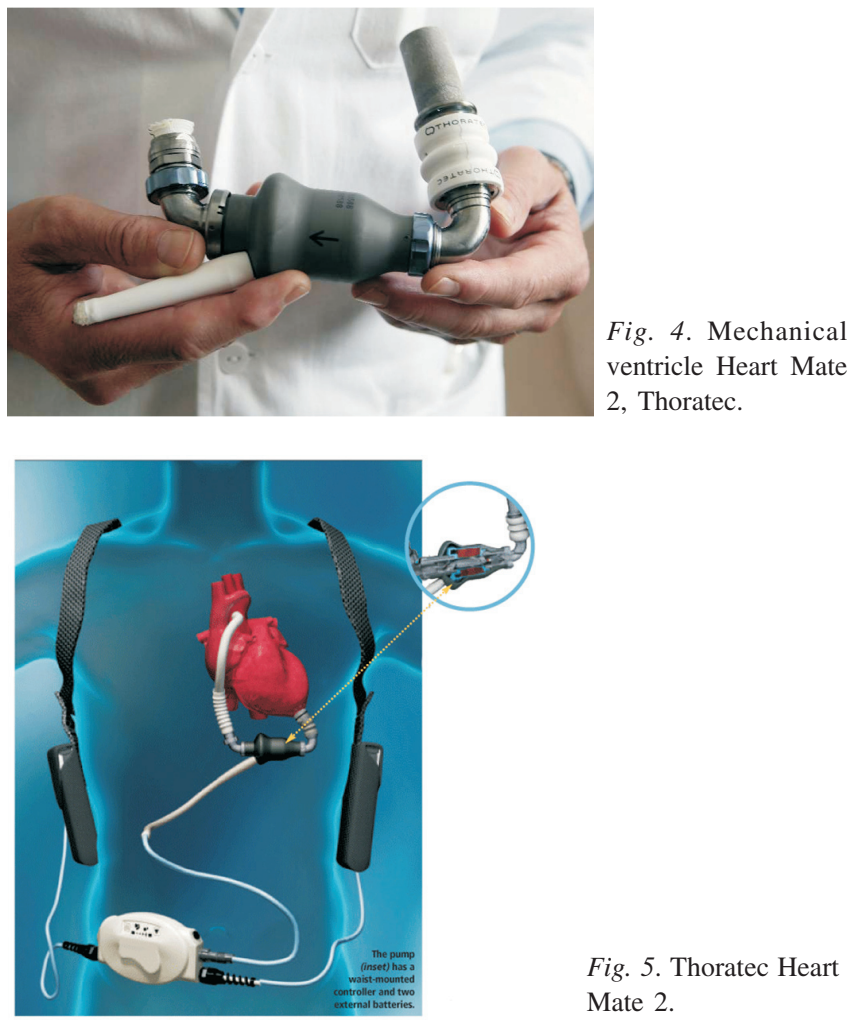

Fig. 5. Thoratec Heart Mate 2.

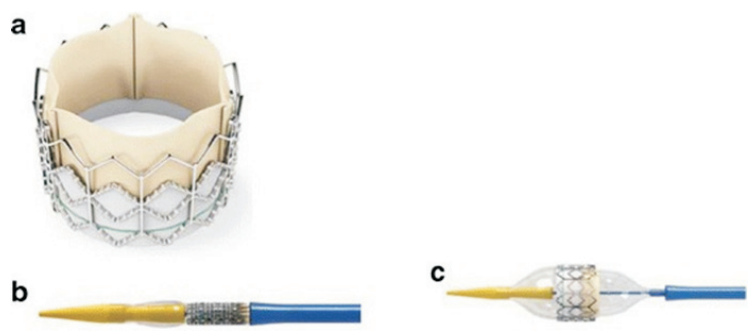

Fig. 6. TAVI Edwards Sapien transcatheter heart Valve.

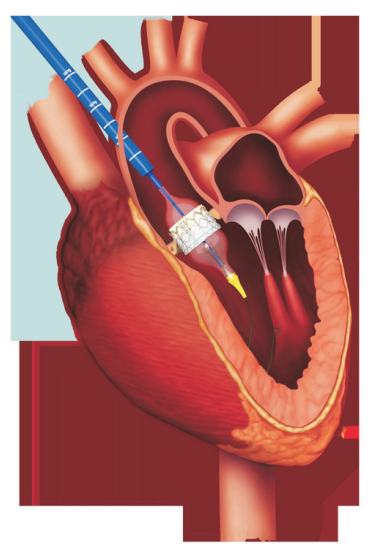

Fig. 7. Aortic insertion of the TAVI heart valve. 